\title{
Impact of urbanization on rainfall-runoff processes: case study in the Liangshui River Basin in Beijing, China
}

\author{
Zongxue $\mathrm{Xu}^{1,2}$ and Gang $\mathrm{Zhao}^{1,2}$ \\ ${ }^{1}$ College of Water Sciences, Beijing Normal University, Beijing 100875, China \\ ${ }^{2}$ Key Laboratory of Water and Sediment Sciences, Ministry of Education, Beijing 100875, China
}

Correspondence to: Zongxue Xu (zongxuexu@vip.sina.com)

Published: 12 May 2016

\begin{abstract}
China is undergoing rapid urbanization during the past decades. For example, the proportion of urban population in Beijing has increased from 57.6\% in 1980 to $86.3 \%$ in 2013. Rapid urbanization has an adverse impact on the urban rainfall-runoff processes, which may result in the increase of urban flood risk. In the present study, the major purpose is to investigate the impact of land use/cover change on hydrological processes. The intensive human activities, such as the increase of impervious area, changes of river network morphology, construction of drainage system and water transfer, were considered in this study. Landsat TM images were adopted to monitor urbanization process based on Urban Land-use Index (ULI). The SWMM model considering different urbanized scenarios and anthropogenic disturbance was developed. The measured streamflow data was used for model calibration and validation. Precipitation with different return periods was taken as model input to analyse the changes of flood characteristics under different urbanized scenarios. The results indicated that SWMM provided a good estimation for storms under different urbanized scenarios. The volume of surface runoff after urbanization was 3.5 times greater than that before urbanization; the coefficient of runoff changed from 0.12 to 0.41 , and the ratio of infiltration decreased from 88 to $60 \%$. After urbanization, the time of overland flow concentration increased while the time of river concentration decreased; the peak time did not show much difference in this study. It was found that the peak flow of 20-year return-period after urbanization is greater than that of 100-year return-period before urbanization. The amplification effect of urbanization on flood is significant, resulting in an increase of the flooding risk. These effects are especially noticeable for extreme precipitation. The results in this study will provide technical support for the planning and management of urban storm water and the evaluation on Low Impact Development (LID) measures.
\end{abstract}

\section{Introduction}

Urbanization is an important index to reflect the development level of a country, but it also enhances the interaction between human society and the environment. The unbalance of the water conservancy facilities transformation and the rapid urban development resulted in considerable urban water problems in China. From 2008 to 2010, different kinds of floods and inundation disasters occurred in $62 \%$ of cities in China. For example, the heavy rainfall on 21 July 2012 in Beijing, resulted in 63 severe urban inundations and claimed the lives of 79 people.
Urbanization increases the risk of flooding due to increased peak discharge and volume, and decreased time to peak that restricted the development of cities (Nirupama and Simonovic, 2007; Saghafian et al., 2008). In highly urbanized areas, over half of rainfall becomes surface runoff, and deep infiltration is only a small fraction of natural situation (Chester et al., 1998). However, some researchers did not found significant changes in runoff coefficients in an urbanized catchment (Brun and Band, 2000; Chang, 2003). Rainfall-runoff process is known to be related to complex factors in urban catchment, such as land use/cover, river network morphology, construction of drainage system and water transfer. The complexity of underlying surface, the un- 
certainty of anthropogenic disturbance, and the lack of highquality datasets for calibration and validation may limit our research for the rainfall-runoff processes in an urban catchment. Thus, there is an urgent need to develop a hydrological model to identify the impact on urbanization with a support of long-term monitoring data in a typical urbanized catchment.

A variety of hydrological models have been developed and applied to simulate rainfall-runoff processes in urban area, including SWMM, MIKE, HSPF, STORM and INFOWORKS. For instance, Guan et al. (2015) used the SWMM model to simulate a series of scenarios in a developing urban catchment. Koudelak and West (2008) and Peng et al. (2015) adopted the InfoWorks model to simulate sewerage network flow in the city of Latvia and China, respectively. Guo et al. (2013) and Alam et al. (2014) used MIKE model to assess flood hazard combined sewer system in urban areas.

In this study, SWMM model considering different urbanized scenarios and anthropogenic disturbance was developed on the basis of remote sensing image and survey. The measured streamflow data was used for model calibration and validation. Precipitation with different return periods was taken as model input to analyse the changes of rainfall-runoff process under different urbanized scenarios.

\section{Study area description}

Dahongmen catchment (Fig. 1) is located in the upstream of Liangshui River basin in Beijing, between $39^{\circ} 48^{\prime}-39^{\circ} 55^{\prime} \mathrm{N}$, $116^{\circ} 9^{\prime}-116^{\circ} 24^{\prime} \mathrm{E}$ and with an area of $131 \mathrm{~km}^{2}$. The terrain in the catchment shows a downward trend from the western mountains to the eastern plains. The annual average precipitation is $522.4 \mathrm{~mm}$ and $80 \%$ of precipitation occurs during the period from June to September. Dahongmen catchment, which has experienced a rapid urbanization process over the past two decades, has gradually become a transport hub and core zone of Beijing metropolitan. Floods and inundation frequently occur in this area, which was further intensified after rapid urbanization. For the purpose to solve this problem, a set of anthropogenic measures including water transfer, river and sewer system, and morphology changes were taken. However, these measures further changed the local rainfall runoff processes.

\section{Model and data description}

\subsection{SWMM model}

The EPA Storm Water Management Model (SWMM) is a dynamic rainfall-runoff simulation model used for single event or long-term (continuous) simulation of runoff quantity and quality from primarily urban areas. It was first developed in 1971 and continued to be widely used throughout the world for planning, analysis and design related to storm water, com-

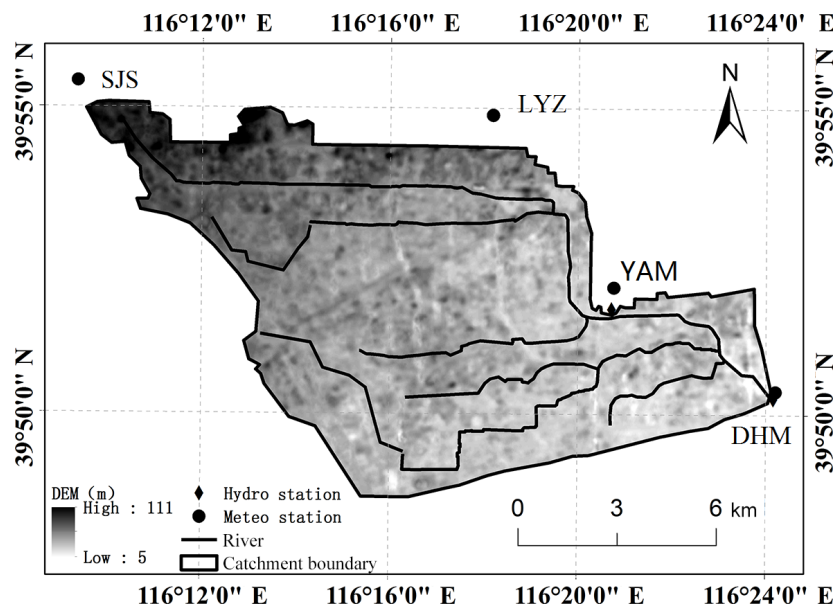

Figure 1. Location, river systems, and hydrometeorological stations in the Dahongmen catchment.

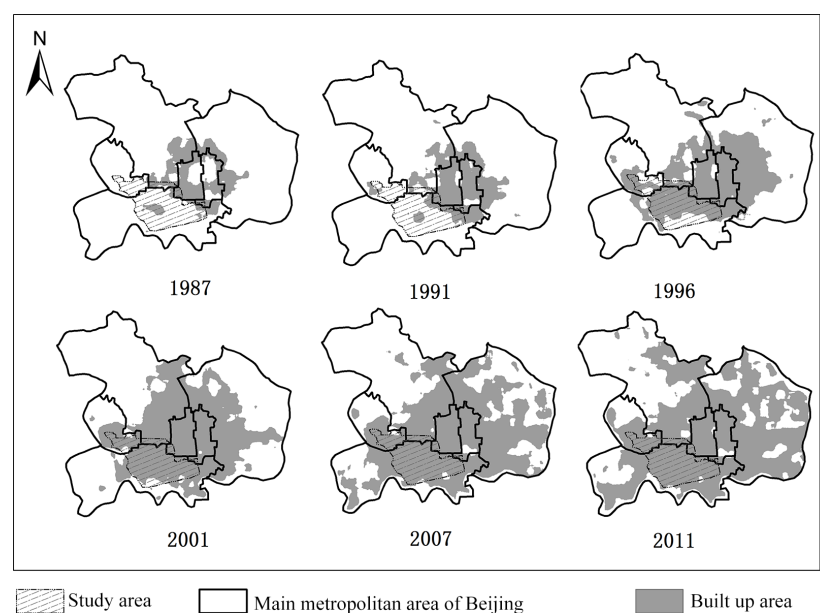

Figure 2. Urbanization processes in the Dahongmen catchment.

bined sewers, and other hydraulic structures in urban areas. The main components of SWMM include surface runoff, infiltration, surface concentration, channel and pipe concentration and LID controls. Further technical details of the model are given by Rossman et al. (2015).

\subsection{Data description}

In this study, urban land-use index (ULI) was used to monitor the urbanization process of Dahongmen catchment in Beijing (Fig. 2). ULI is an effective index automatically extracting from urban land uses with Landsat 7 image. It reduces the impact of low density vegetation on extraction accuracy. According to Fig. 2, the study area has experienced rapid urbanization process from 1987 to 2011, and the proportion of impervious area in SWMM model is set based on ULI index.

Digital Elevation Model (DEM) and sewer system map were provided by the National Aeronautics and Space Ad- 
Table 1. Results of parameter identification.

\begin{tabular}{llrr}
\hline Parameters in SWMM & Before urbanization & After urbanization \\
\hline Manning coefficient & Pervious zone & 0.43 & 0.36 \\
& Impervious zone & 0.07 & 0.04 \\
& Channels & 0.025 & 0.048 \\
& Pipeline & - & 0.02 \\
\hline \multirow{2}{*}{ Horton coefficient } & Maximum infiltration & 124.6 & 142.4 \\
& minimum infiltration & 74.7 & 89.6 \\
& Decay coefficient & 11.4 & 23.2 \\
\hline
\end{tabular}

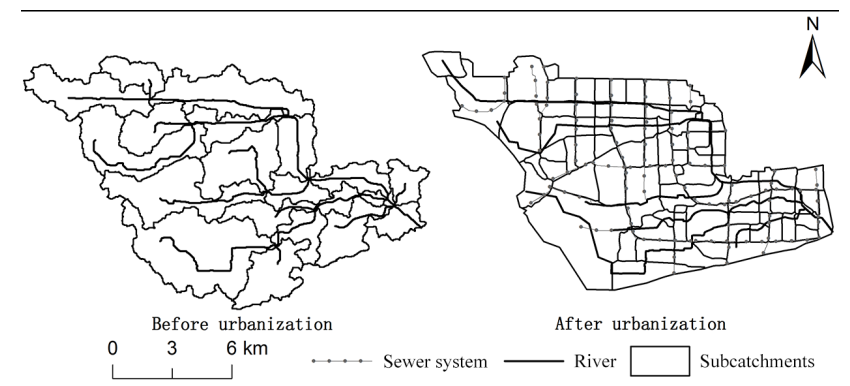

Figure 3. Model development in different urbanization cases.

ministration (NASA, ASTER GDEM) and Beijing Municipal Institute of City Planning and Design. Hourly precipitation series at 4 stations (Fig. 1) and streamflow data at DHM station from 1980 to 2012 were obtained from the Hydrographic Station of Beijing. Hourly inflow data of YAM station were obtained from the Liangshui River Basin Authority.

\section{Model development}

\subsection{Catchment subdivision}

Catchment subdivision should reflect the urbanization process and has great impacts on the rainfall runoff simulation. Before urbanization, DEM and D8 algorithm were used to extract the subcatchment (Fig. 3). But for highly developed urban area, catchment was divided by design drainage areas provided by the Beijing Municipal Institute of City Planning and Design.

\subsection{Model accuracy evaluation}

According to the standard for hydrological information and hydrological forecasting in China, Nash-Sutcliffe efficiency coefficient $\left(R_{\mathrm{NS}}\right)$, relative error of flood peak discharge $\left(\mathrm{RE}_{\mathrm{p}}\right)$ and absolute error of flood peak appearance $\left(\mathrm{AE}_{\mathrm{T}}\right)$ were used for measuring the accuracy of model performance.

$$
R_{\mathrm{NS}}=1-\frac{\sum_{i=1}^{N}\left(q_{\mathrm{t}}^{\mathrm{obs}}-q_{\mathrm{t}}^{\mathrm{sim}}\right)^{2}}{\sum_{i=1}^{N}\left(q_{\mathrm{t}}^{\mathrm{obs}}-\bar{q}^{\mathrm{obs}}\right)^{2}},
$$

where $q_{\mathrm{t}}^{\text {obs }}$ is observed discharge sequence, $N$ is the number of observed discharge data and $\bar{q}^{\text {obs }}$ is the average of the observed discharge.

$\mathrm{RE}_{\mathrm{p}}=\frac{\left|q_{\mathrm{p}}^{\mathrm{obs}}-q_{\mathrm{p}}^{\text {sim }}\right|}{q_{\mathrm{p}}^{\text {obs }}} \times 100 \%$,

where $q_{\mathrm{p}}^{\text {obs }}$ is the observed peak flow, $q_{\mathrm{p}}^{\text {sim }}$ is the simulated peak flow.

$\mathrm{AE}_{\mathrm{T}}=T_{\mathrm{p}}^{\mathrm{obs}}-T_{\mathrm{p}}^{\mathrm{sim}}$,

where $T_{\mathrm{p}}^{\mathrm{obs}}$ is the observed occurrence time of flood peak, $T_{\mathrm{p}}^{\mathrm{sim}}$ is the simulated occurrence of flood peak.

\section{Results analysis}

\subsection{Model calibration and validation}

Most of the parameters in SWMM model have its specific physical meaning, which can be measured theoretically. Due to the limitation of data, these parameters are usually determined by empirical method or optimization method. In this study, the genetic algorithm (GA) was adopted to optimize the sensitive parameters in SWMM model, and NashSutcliffe efficiency ( $R_{\mathrm{NS}}$ ) was used as the objective function. Results of parameter identification are given in Table 1.

Manning coefficient in both pervious and impervious area decreased after urbanization, it shows that the concentration time of overland flow declined. However, the increase in manning roughness coefficient of channel suggested that the concentration time of river raised after urbanization. Horton infiltration coefficient reflects the infiltration capacity of pervious zone, which changes little after urbanization. Error statistics of simulation results and flood hygrograph are shown in Table 2, Figs. 4 and 5. 
Table 2. Error statistics of simulation results.

\begin{tabular}{llrr|rr}
\hline & \multicolumn{3}{c|}{ Calibration } & \multicolumn{2}{c}{ Validation } \\
\hline Before urbanization & Storm & 19810703 & 19830619 & 19850702 & 19870813 \\
& $R_{\mathrm{NS}}$ & 0.62 & 0.61 & 0.83 & 0.64 \\
& $\mathrm{RE}_{\mathrm{p}}$ & $3 \%$ & $3 \%$ & $6 \%$ & $15 \%$ \\
& $\mathrm{AE}$ & -1 & 0 & 0 & +1 \\
\hline \multirow{2}{*}{ After urbanization } & $\mathrm{Storm}$ & 20110623 & 20120721 & 20110814 & 20110726 \\
& $R_{\mathrm{NS}}$ & 0.88 & 0.95 & 0.84 & 0.60 \\
& $\mathrm{RE}_{\mathrm{p}}$ & $2 \%$ & $2 \%$ & $11 \%$ & $4 \%$ \\
& $\mathrm{AE}_{\mathrm{T}}$ & 0 & 0 & +1 & 0 \\
\hline
\end{tabular}

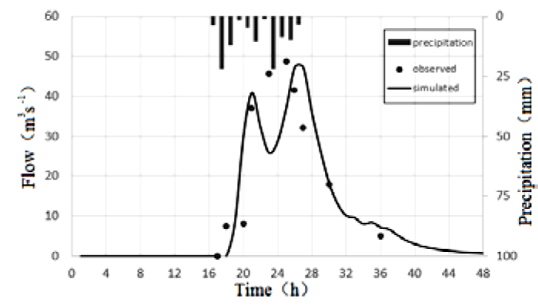

(a) Storm 19810703

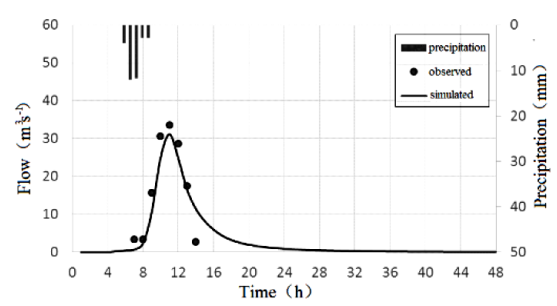

(c) Storm 19850702

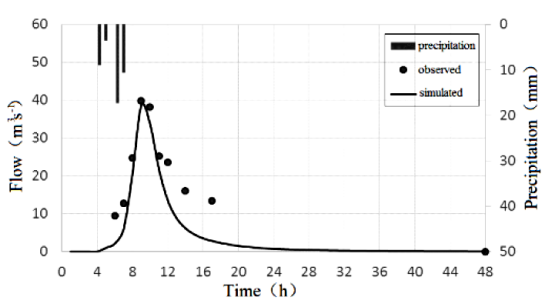

(b) Storm 19830619

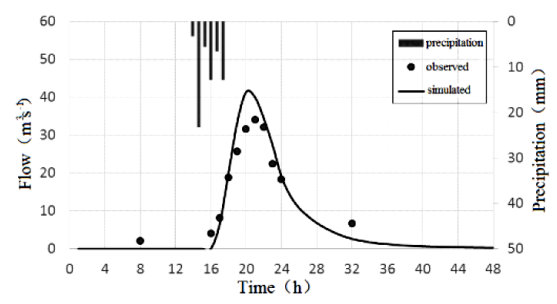

(d) Storm 19870813

Figure 4. Simulation of flood before urbanization.

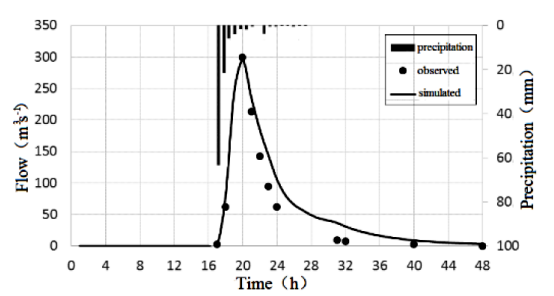

(a) Storm 20110623

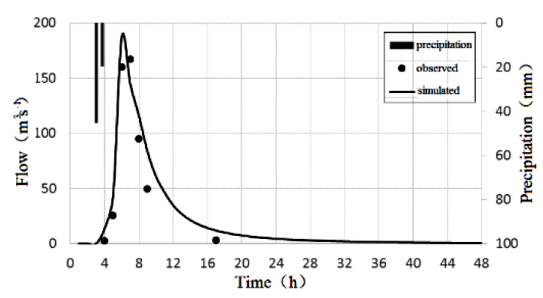

(c) Storm 20110814

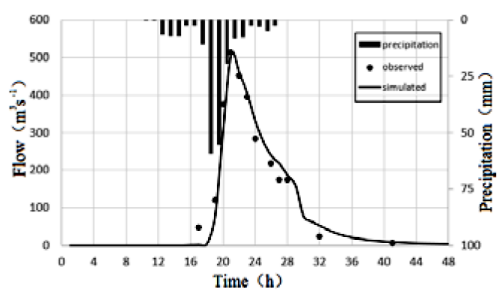

(b) Storm 20120721

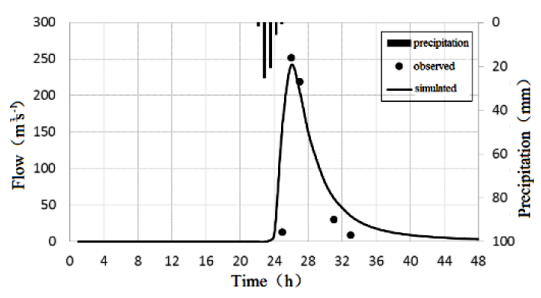

(d) Storm 20110726

Figure 5. Simulation of flood after urbanization. 
Table 3. Changes of rainfall-runoff processes in different scenarios.

\begin{tabular}{lrr|rr|rr|r|r|r|r|r}
\hline \multirow{2}{*}{ Hydrological Various } & \multicolumn{2}{c}{$P=100 \%$} & \multicolumn{2}{c|}{$P=20 \%$} & \multicolumn{2}{c|}{$P=5 \%$} & \multicolumn{2}{c}{$P=2 \%$} & \multicolumn{2}{c}{$P=1 \%$} \\
\cline { 2 - 12 } & before & after & before & after & before & after & before & after & before & after \\
\hline Precipitation (mm) & 47.7 & 47.7 & 150.4 & 150.4 & 260.3 & 260.3 & 335.9 & 335.9 & 395.0 & 395.0 \\
Runoff (mm) & 5.5 & 14.6 & 17.9 & 66.3 & 30.3 & 109.8 & 40.0 & 136.3 & 48.6 & 161.1 \\
Runoff-Coefficient & 0.12 & 0.31 & 0.12 & 0.44 & 0.12 & 0.42 & 0.12 & 0.41 & 0.12 & 0.41 \\
Peak flow (m ${ }^{3} \mathrm{~s}^{-1}$ ) & 30.6 & 64.3 & 118.7 & 337.4 & 208.5 & 438.6 & 298.8 & 526.7 & 384.9 & 612.8 \\
Peak time (h) & $3 \mathrm{~h}$ & $5 \mathrm{~h}$ & $2 \mathrm{~h}$ & $3 \mathrm{~h}$ & $2 \mathrm{~h}$ & $2 \mathrm{~h}$ & $2 \mathrm{~h}$ & $2 \mathrm{~h}$ & $2 \mathrm{~h}$ & $2 \mathrm{~h}$ \\
\hline
\end{tabular}

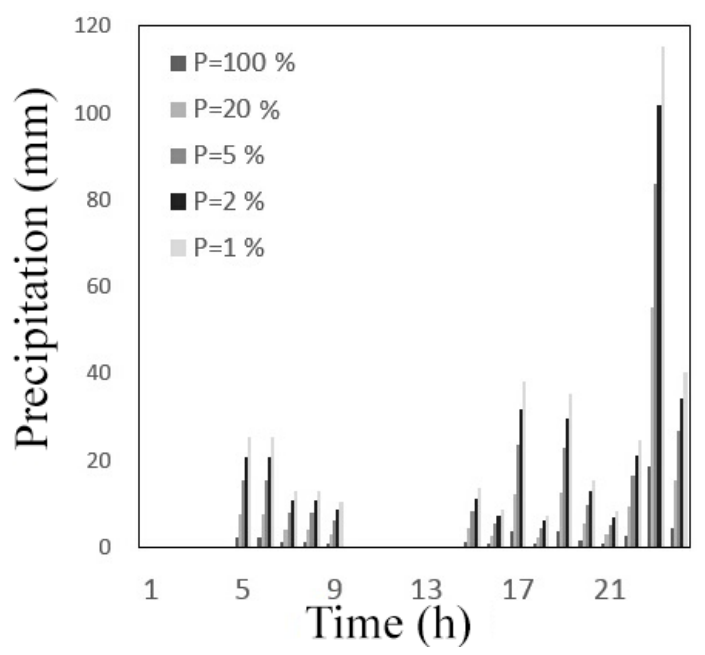

Figure 6. 24-h rainfall processes at different frequency.

As can be seen, Nash-Sutcliffe efficiency is greater than 0.6 and the relative error of the peak flow is smaller than $15 \%$ in both calibration and validation periods, which means that SWMM provided a good estimation both pre- and posturbanization. Moreover, the simulation results after urbanization are much better than before, particularly on the occurrence time of flood peak.

\subsection{Rainstorm scenario analysis}

According to the hydrological handbook in Beijing, the design storms with different return periods $(p=100 \%, p=$ $20 \%, p=5 \%, p=2 \%, p=1 \%$ ) were calculated based on design rainfall formula and the 24 -h rainfall distribution. The results of design storms are given in Fig. 6. Changes of floods in different urbanization scenarios were simulated with these input precipitation data and the results are shown in Fig. 7 and Table 3.

According to Table 3, the urbanization process has a significant amplification effect on runoff generation. Taking 100-year return-period $(p=1 \%)$ as an example, the surface runoff after urbanization is $395 \mathrm{~mm}$, which is 3.55 times than
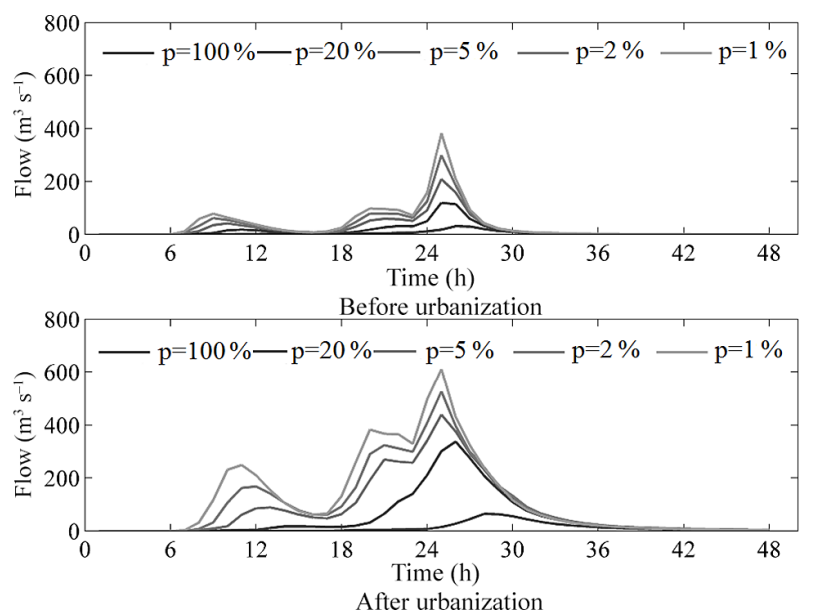

Figure 7. Changes of floods in different urbanization scenarios.

that before urbanization. The runoff coefficient increased from 0.12 to 0.41 , and the infiltration after urbanization covers $65 \%$ of that before urbanization; however, the peak flow after urbanization is 1.68 times than that before urbanization. Therefore, the amplification effect of urbanization on lowfrequency flood is obvious, resulting in an increase of the flooding risk in urban area.

However, the flood peak did not appear earlier, and even delayed on high-frequency precipitation $(p=100 \%$ and $p=20 \%$ ). Field investigation found that there are many artificial river barrages (such as bridges, gates or embankments) which delayed the time of channel concentration. On the other hand, the runoff flowed along the artificial path after urbanization, which makes it faster but longer than that before urbanization, and hence influenced the peak time. It is also found that the peak flow of 20-year return-period after urbanization is higher than that of 100-year return-period before urbanization, which puts forward new requirements and challenges for the transformation of urban facilities and urban water management. 


\section{Conclusions}

In this study, the SWMM model considering different urbanized scenarios and anthropogenic disturbance was successfully applied to simulate the rainfall-runoff process in Dahongmen catchment, Beijing. The measured streamflow data was used for model calibration and validation. Precipitation with different return periods was used as model input to analyse the changes of flood characteristics under different urbanized scenarios. Major conclusions can be summarized as follows:

1. SWMM model has good performance for the simulation of rainfall-runoff process before and after urbanization. Nash-Sutcliffe efficiency is greater than 0.6, and the relative error of flood peak discharge is smaller than $15 \%$ both during calibration and validation periods.

2. The volume of surface runoff after urbanization was 3.5 times greater than that before urbanization; the coefficient of runoff changed from 0.12 to 0.41 , and the ratio of infiltration decreased from 88 to $60 \%$. The amplification effect of urbanization for low-frequency precipitation is more obvious and the peak flow of 20 -year return-period $(5 \%)$ after urbanization is higher than that of 100-year return-period (1\%) before urbanization, leading to a higher flood risk in urban area.

3. The occurrence time of flood peak shows little change after urbanization. The concentration of overland flow accelerates and the river concentration had grown over time after urbanization. Therefore, the occurrence time of flood peak did not appear in advance or even delayed on high-frequency precipitation $(p=100 \%$ and $p=20 \%$ ), mainly due to the growing number of artificial river barrages in the study area.
Acknowledgements. This study was financially supported by the key project of Beijing Natural Science Foundation (8141003).

\section{References}

Alam, S., Willems, P., and Alam, M.: Comparative Assessment of Urban Flood Risks Due to Urbanization and Climate Change in the Turnhout Valley of Belgium, J. Adv. Res., 3, 14-23, 2014.

Brun, S. E. and Band, L. E.: Simulating runoff behavior in an urbanizing watershed, Comput. Environ. Urban, 24, 5-22, 2000.

Chang, H.: Basin Hydrologic Response to Changes in Climate and Land Use: the Conestoga River Basin, Pennsylvania, Phys. Geogr., 24, 222-247, 2003.

Chester, L., Arnold, J. C., and James, G.: Impervious Surface Coverage: The Emergence of a Key Environmental Indicator, J. Am. Plann. Assoc., 62, 243-258, 1998.

Guan, M., Sillanpää, N., and Koivusalo, H.,: Modelling and assessment of hydrological changes in a developing urban catchment, Hydrol. Process., 29, 2880-2894, 2015.

Guo, F., Hanfei, Q. U., Zeng, H., Cong, P., and Geng, X.: Flood hazard forecast of Pajiang River flood storage and detention basin based on MIKE21, J. Nat. Disasters, 22, 144-152, 2013.

Koudelak, P. and West, S.: Sewerage network modelling in Latvia, use of InfoWorks CS and Storm Water Management Model 5 in Liepaja city, Water Environ. J., 22, 81-87, 2007.

Nirupama, N. and Simonovic, S. P.: Increase of Flood Risk due to Urbanization: A Canadian Example, Nat. Hazards, 40, 25-41, 2007.

Peng, H. Q., Liu, Y., Wang, H. W., and Ma, L. M.: Assessment of the service performance of drainage system and transformation of pipeline network based on urban combined sewer system model, Environ. Sci. Pollut. R., 22, 15712-15721, 2015.

Rossman, L. A.: Storm Water Management Model User's Manual Version 5.0, EPA United States Environmental Protection Agency, 2015.

Saghafian, B., Farazjoo, H., Bozorgy, B., and Yazdandoost, F.: Flood Intensification due to Changes in Land Use, Water Resour. Manag., 22, 1051-1067, 2008. 